\title{
A case of nonalcoholic Wernicke's encephalopathy due to an extreme diet based on magnetic resonance imaging features
}

Julius July, ${ }^{1}$ Adeline, ${ }^{2}$ Girianto Tjandrawidjaja, ${ }^{3}$ Yusak Mangara Tua Siahaan, ${ }^{3}$ Allen Widysanto, ${ }^{4}$ Hori Hariyanto, ${ }^{5}$ Rusli Muljadi $^{6}$

pISSN: 0853-1773 • elSSN: 2252-8083 https://doi.org/10.13181/mji.v28i3.2629 Med J Indones. 2019;28:276-9

Received: May 05, 2018

Accepted: July 16, 2019

\section{Authors' affiliations:}

${ }^{1}$ Department of Neurosurgery, Faculty of Medicine, Universitas Pelita Harapan, Tangerang, Indonesia, ${ }^{2}$ Faculty of Medicine, Universitas Pelita Harapan, Tangerang, Indonesia, ${ }^{3}$ Department of Neurology, Faculty of Medicine, Universitas Pelita Harapan, Neuroscience Centre Siloam Hospital Lippo Village, Tangerang, Indonesia, ${ }^{4}$ Department of Internal Medicine, Faculty of Medicine, Universitas Pelita Harapan, Neuroscience Centre Siloam Hospital Lippo Village, Tangerang, Indonesia, ${ }^{5}$ Department of Anesthesiology, Faculty of Medicine, Universitas Pelita Harapan, Neuroscience Centre Siloam Hospital Lippo Village, Tangerang, Indonesia, ${ }^{6}$ Department of Radiology, Faculty of Medicine, Universitas Pelita Harapan, Neuroscience Centre Siloam Hospital Lippo Village, Tangerang, Indonesia

\section{Corresponding author:}

Julius July

Department of Neurosurgery, Faculty of

Medicine, Universitas Pelita Harapan, Neuroscience Centre Siloam Hospital Lippo Village, Jalan Siloam 6, Lippo Village, Tangerang 15811, Indonesia Tel/Fax: +62-21-1500181 ext. 6620, $6623 /+62-21-5460921$

E-mail: juliusjuly@yahoo.com

\begin{abstract}
Wernicke's encephalopathy is a rare occurrence in Indonesia because alcohol consumption is very low. However, in Indonesia, Wernicke's encephalopathy could be triggered by an inadequate intake of thiamine (vitamin B1) due to an extreme diet for several months. It is a case of a 31-year-old male, who presented to the emergency room with a decreased level of consciousness. According to the family, for the last few weeks, he has become less responsive and less attentive. Fluidattenuated inversion recovery (FLAIR) magnetic resonance imaging (MRI) revealed a unique picture with symmetrical lesions in the bilateral medial thalamus, mammillary bodies, periaqueductal gray matter, and the dorsal surface of the medulla oblongata. Clinically, there is no neck stiffness and no fever. The laboratory results from the blood and cerebrospinal fluid have ruled out meningitis. Treatment with thiamine 200 mg t.i.d. has shown an excellent response and significant clinical improvement. The earlier thiamine substitution treatment is started, the better the outcome because thiamine will prevent further injury to the brain and enhance recovery.
\end{abstract}

KEYWORDS deficiency, fasting, thiamine, Wernicke's encephalopathy
Wernicke's encephalopathy (WE) is a reversible biochemical brain lesion caused by the imbalance in metabolic demands on the brain, which has a deficient amount of thiamine (vitamin B1) leading to an acute neuropsychiatric condition. ${ }^{1}$ It is characterized by the acute onset of confusion, nystagmus, partial ophthalmoplegia, and ataxia. ${ }^{2}$ WE may lead to permanent brain damage involving severe short-term memory loss, also known as Korsakoff's psychosis. WE is the result of inadequate intake or absorption of thiamine, along with continuous carbohydrate ingestion. This state is mostly found in people who are alcoholics but rarely seen in prolonged undernutrition or vitamin deficiency caused by chronic dialysis, hyperemesis, starvation, gastric plication, cancer, and AIDS. It is a case of WE due to an extreme diet. 


\section{Case report}

The family provide a consent for us to write this case report. The individual is a 31-year-old male who arrived with an altered level of consciousness. Prior to that, his family mentioned that he had double vision before he became less attentive and less responsive for the last two weeks. He has been known for his strange dietary behavior that included one day of eating and one day of fasting, with incremental days of fasting. During the last two months, he was fasting for six days and eating for one day. During his fasting days, he only drank still water. He lost $20 \mathrm{~kg}$ in the last six months, and his initial body mass index, which was $25 \mathrm{~kg} / \mathrm{m}^{2}$, decreased to $17.6 \mathrm{~kg} / \mathrm{m}^{2}$. In addition, he has shown abnormal behavior for the last two months. His wife noticed that he was unable to move his eyes and had been troubled by double vision. When conversed with, he was less attentive and less responsive. During his admission to the other hospital, he went into a comatose state and was transferred to the emergency room.

Through physical examination to locate pain, he opened his eyes in response to painful stimuli and made incoherent sounds (Glasgow coma scale 12). His left side was slightly weaker compared with his right side. He had no neck stiffness and no fever. The laboratory study on his blood was normal except for a slight leukocytosis. His computerized tomography scan from the previous hospital did not show any obvious abnormality. The cerebrospinal fluid study results have ruled out meningitis. The fluid-attenuated inversion recovery (FLAIR) magnetic resonance imaging (MRI) of his brain was unique. It revealed symmetrical hyperintense lesions in the bilateral medial thalamus, mammillary bodies, periaqueductal gray matter, and the dorsal surface of the medulla oblongata (Figure 1). The results are very specific to WE. ${ }^{2}$ Ideally, the thiamine level in the blood were checked to prove the case, but the test is uncommon, and it might even further delay treatment. The decision was to proceed with treatment based on the clinical presentation and MRI features.

Treatment was initiated with intravenous thiamine injection of $200 \mathrm{mg}$ three times a day. He showed remarkable improvement after two days of treatment and could then open his eyes and obey commands such as showing his tongue. The following day, the patient could then say his name and follow some simple commands. One week
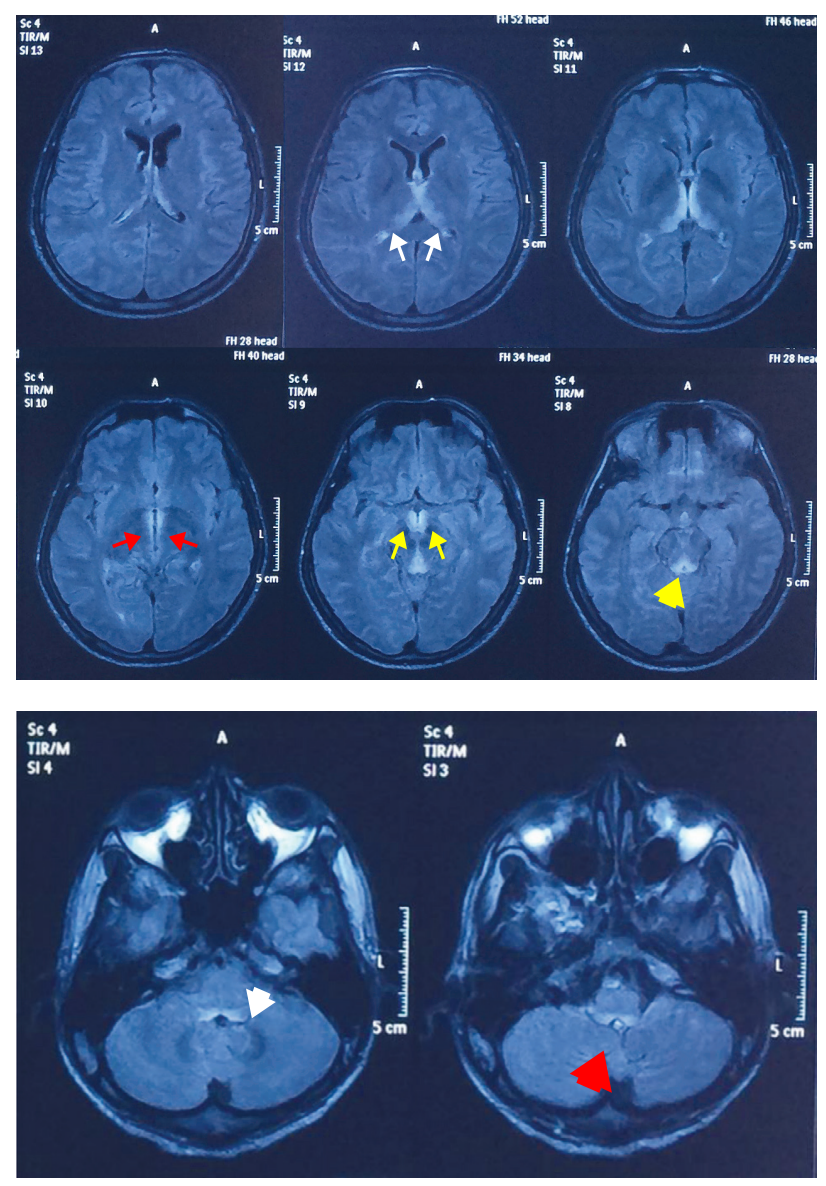

Figure 1. Brain FLAIR MRI shows symmetrical hyperintense lesions in both medial thalami (white arrows), the lateral walls of the third ventricle (red arrows), the mammillary bodies (yellow arrows), the periaqueductal gray matter (yellow arrowhead), the medial vestibular nuclei (white arrowhead), and the prepositus hypoglossal nuclei (red arrowhead). FLAIR=fluid-attenuated inversion recovery; MRI=magnetic resonance imaging

following the treatment, he gained his full conscious level, being able to communicate, and was fully oriented. His muscle strength was improving, in both his upper and lower extremities. The treatment is to keep him on thiamine injections for one week and then converted to oral thiamine at a dose of $250 \mathrm{mg}$ per day for one month. When he visited outpatient clinic six months after the initial treatment, he could communicate well, his motor power reached 4+ for all his extremities, and the dose of thiamine were reduced to $10 \mathrm{mg}$ per day indefinitely.

\section{DISCUSSION}

Wernicke's encephalopathy (WE) is a neuropsychiatric condition characterized by nystagmus, abducens nerve and conjugate gaze 
palsies, ataxia of gait, and mental confusion. ${ }^{3}$ It results from a deficiency in thiamine and has been found mainly in alcoholics. In some cases, this disease was also found in people with nutritional deficiency and was immediately followed by Korsakoff amnesia, in which retentive memory is out of proportion to all other cognitive functions in an otherwise alert and responsive patient. If the manifestation was complexed with a defect in learning and memory retention, then it was called Wernicke-Korsakoff syndrome.

Though it was recognized mainly due to alcoholism, other states may lead to this disease such as hyperemesis gravidarum, anorexia nervosa, starvation, and other similar things. This case is unusual because it features the practice of an extreme diet, and is based on a recent communication with the patient, which was reliable. He was trying to force himself to learn supernatural powers by doing this extreme diet. He also mentioned that he was almost successful and acquired some supernatural powers to communicate with the dead after several months. We believe that it is because of his mental changes during the encephalopathy that caused hallucinations before he collapsed and became unconscious.

In alcoholic patients, the deficiency of thiamine was mainly caused by its increased requirement due to carbohydrate intake, and the body can store only around 30-50 mg of thiamine. This can also occur in a patient who is found to be on a deficient diet for about four weeks, but it can vary. ${ }^{4}$ In this case, it happened after several months of extreme fasting. The patient started with alternating fasting and eating, and then the fasting portion was extended for seven days until he finally collapsed. There will not be enough thiamine in his diet, and the severe malnutrition that followed the fasting will further interfere with the absorption of thiamine from his gastrointestinal tract. Thiamine is mainly needed by brain cells. However, it must undergo several steps, such as uptake by the brush border in the intestine to enter the enterocytes in the blood. It then crosses the blood-brain-barrier to reach the neuron and is transported into the mitochondria. ${ }^{4}$ Thiamine is a cofactor needed for lactic acid dehydrogenase to convert lactic acid into pyruvic acid (pyruvate). Then, the pyruvic acid will enter the oxidative cycle, and end with the synthesis of ATP (the source of energy). Without an adequate amount of thiamine, metabolically active tissue cannot synthesize ATP to form glucose and will retain lactic acid. Understanding this pathway enables physicians to ensure that treatment using dextrose is prohibited because it will exacerbate the condition. ${ }^{5}$

Inadequate intake, such as in anorexia nervosa, has been reported as a severe cause of WE. ${ }^{6}$ It also was mentioned that WE could be due to a water-only fasting diet, ${ }^{7}$ which is very understandable that such a diet will cause malnutrition. This case is very specific because the patient was intentionally doing the extreme diet for supernatural purposes, which to the authors' knowledge have never been scientifically reported.

Oculomotor abnormalities are a very common initial sign. They could present as nystagmus in either the horizontal or the vertical direction. In addition, weakness in the lateral rectus muscle and conjugate gaze are present. These symptoms are highly characteristic of Wernicke's disease and their disappearance by giving thiamine confirms the diagnosis. The disturbance of consciousness usually starts as a sign of a confused state. Drowsiness is common and may progress to stupor, and then to a comatose state. In response to the administration of thiamine, the patient rapidly becomes more alert and attentive and can have a conversation. ${ }^{8}$

If left untreated, the condition may worsen to the amnestic state in which the patient will have difficulty in learning (anterograde amnesia) and loss of memories (retrograde amnesia). The conscious state may develop into the worst-case scenario and eventually lead to death. ${ }^{4}$ Before death, they will progressively lose brainstem function, have difficulty swallowing even their own saliva, thereby making them susceptible to lung infections due to aspiration.

Treatment of this condition should not be delayed. Administration of thiamine prevents progression of the disease and may eventually reverse the defects that are not fixed yet. The recommended thiamine dosage to be given is 50-200 mg intravenously initially and repeated intramuscularly or intravenously. Continuous administration is needed until the patient regains the ability to consume a regular diet. In some investigations, it is beneficial to administer a higher dose over several days. Magnesium may also be given, as it is a cofactor for thiamine activity. ${ }^{9}$ 
In conclusion, although it is rare, nonalcoholic WE needs to be considered if the patient has a recent history of an extreme diet. Diagnosis by FLAIR MRI is key and confirmed by the disappearance of symptoms with thiamine administration.

\section{Conflict of Interest}

The authors affirm no conflict of interest in this study.

\section{Acknowledgment}

None.

\section{Funding Sources}

None.

\section{REFERENCES}

1. Guler A, Alpaydin S, Sirin H, Calli C, Celebisoy N. A non-alcoholic Wernicke's encephalopathy case with atypical MRI findings: clinic versus radiology. Neuroradiol J. 2015;28(5):474-7.

2. Galvin R, Bråthen G, Ivashynka A, Hillbom M, Tanasescu R, Leone MA. EFNS guidelines for diagnosis, therapy and prevention of Wernicke encephalopathy. Eur J Neurol.
2010;17(12):1408-18.

3. Ropper AH, Samuel MA, Klein JP, Prasad S. Adam and Victor's principles of neurology. $10^{\text {th }}$ Ed. New York: McGraw-Hill; 2014:1161-7.

4. Mkrtchyan G, Aleshin V, Parkhomenko Y, Kaehne T, Di Salvo ML, Parroni A, et al. Molecular mechanisms of the non-coenzyme action of thiamin in brain: biochemical, structural and pathway analysis. Sci Rep. 2015;5:12583.

5. Schabelman E, Kuo D. Glucose before thiamine for Wernicke encephalopathy: a literature review. J Emerg Med. 2012;42(4):488-94.

6. Oudman E, Wijnia JW, Oey MJ, van Dam MJ, Postma A. Preventing Wernicke's encephalopathy in anorexia nervosa: a systematic review. Psychiatry Clin Neurosci. 2018;72(10):774-9.

7. Hutcheon DA. Malnutrition-induced Wernicke's encephalopathy following a water-only fasting diet. Nutr Clin Pract. 2015;30(1):92-9.

8. Onishi H, Ishida M, Tanahashi I, Takahashi T, Ikebuchi K, Taji Y, et al. Early detection and successful treatment of Wernicke's encephalopathy in outpatients without the complete classic triad of symptoms who attended a psycho-oncology clinic. Palliat Support Care. 2018;16(5):633-6.

9. Dingwall KM, Delima JF, Gent D, Batey RG. Hypomagnesaemia and its potential impact on thiamine utilisation in patients with alcohol misuse at the Alice Springs Hospital. Drug Alcohol Rev. 2015;34(3):323-8. 